base conclusions. Mr. Moynihan himself has, I believe, adopted the no-loop method only within the last two years, too short a period in which to judge of the after results. My contention is that at the present time we are not entitled to maintain that experience is conclusive as to the status of the no-loop method, nor can I admit that "every argument" is in favour of it. The no loop method is, at least so it seems to me, wrong in principle, as it must be mechanically incorrect to unite a portion of the jejunum close to its origin to a moveable organ like the stomach. That this is not a hy potbetical objection is proved by a case recently recorded by Munford ${ }^{1}$ in which death ensued owing to the anastomosis being torn apart by the contraction of the stomach. Such an accident can hardly occur if a loop be left between the origin of the jejunum and the site of the anastomosis.

With regard to the occurrence of internal hernia, $\mathrm{Mr}$. Moynihan asserts that such an occurrence is impossible if the edges of the mesocolon are stitched to the jejunum. Impossible is a strong word to use in connexion with the abdominal cavity, a region about which prophecy is extremely hazardous. Mr. Moynihan hirnself has, so I am informed, adopted this plan for less than two years and since in some of the recorded cases of gastro-jejunostomy (including one of Mr. Moynihan's own) interual hernia has not occurred until after an interval of tro years, surely it is too early to speak positively as to the impossibility of internal hernia when the mesocolon is stitched to the jejunum. In the absence of any direct evidence on the point I think we may be sceptical as to whether the insertion of three stitches will invariably secure permanent and efficient closure of the opening into the lesser sac.

Mr. Moynihan next deals with the subject of regurgitant vomiting. He admits that the obstruction is at the anastomotic opening and then concludes: "The cause of this obstruction I submit, therefore, is to be found in the loop." I confess I do not follow this reasoning. Why if the obstruction be at the anastomotic opening should the loop play any part in its production, unless, indeed, $\mathrm{Mr}$. Moynihan maintains that the obstruction is secondary to "water-logging"? Be this as it may, my contention is that regurgitant vomiting is a preventable complication, and there is no evidence that it is more common after anterior than after posterior gastro-jejunostomy.

Next as to peptic jejunal ulcer. Mr. Moynihan takes exception to my explanation of the fact that more instances of peptic jejunal ulcer have followed the anterior than the posterior operation-namely, that the anterior operation has been more frequently performed. He says, "it is almost certain that the posterior operation has been performed far more frequently." My answer is that a search through the records of the period 1881 to 1904 indicates that the anterior operation had been performed more frequently than the posterior, and the difference is probably sufficient to account for the larger number of jejunal ulcers which have followed the anterior operation. The important point, however, to which Mr. Moynihan does not allude is that peptic jejunal ulcer following the posterior is apparently a more serious complication than after the anterior operation.

Lastly, Mr. Moynihan states that "the choice of the posterior operation is the result of a considered and wellreasoned opinion that it is a safer, and so far as the afterresults are concerned a more successful, operation than the anterior, and established by long experience." Does Mr. Moynihan refer to the posterior operation with or without a loop? If he refers to the "no loop" method, advocated by Czerny and Petersen in 1901, he can scarcely maintain that it is an operation established by long experience. If, on the other hand, he refers to the posterior operation with a loop, I submit that the series of cases brought forward in my lectures shows that there is no evidence that the posterior operation is either safer, or more satisfactory as to the afterresults than the anterior. I adduced records of patients who have lived in perfect health for $10,12,14,18$, and 19 years after anterior gastro-jejunostomy, some of whom have regained and maintained their normal weight. Can the advocates of posterior gastro-jejunostomy wish for better results than these?

Probably the last word has yet to be said as to the best method of performing gastro-jejunostomy, so that opinions, however considered and well-reasoned, must be accepted with caution and not accepted as final until they are supported by a long series of observed facts. For the present
I submit that, whatever may be the case later, there is no conclusive evidence to show that the results, either immediate or remote, are better after the posterior than after the anterior operation. Until such evidence is forthcoming I shall continue to employ the simpler and, in my own experience, perfectly satisfactory anterior operation.

I am, Sirs, yours faithfully,

Herbert J Paterson.

Upper Wimpole-street, W., March 30th, 1906.

\section{THE QUESTION OF PAY HOSPITALS.}

\section{To the Editors of THE LANCET.}

SIRs,- - The general attention which is at the moment directed to schemes for providing public institutions for patients able to pay for their support has brought to light a good deal of evidence of the efforts made to deal with this subject-as long ago as 1881 in the case of St. Thomas's Hospital and 1884 in the case of Guy's Hospital. Smaller institutions may also claim to have to a great extent solved the problem and of these the Hampstead General Hospital was undoubtedly one of the first. Started as a home hospital in 1882 its special feature was that all patients were expected to contribute towards their support. It was found necessary later to provide free beds, the number of which has been increased now that the hospital has removed to the new building at Haverstock Hill. The experience of this institution goes to show that there is real need for beds for paying patients and when in the near future the hospital is enlarged to 115 beds it is intended to provide a special block with 20 beds for patients of this class, entirely separated from the free wards.

The problem is made more difficult by the want of uniformity in hospital methods. Applications for admission here both to beds at the contributing rate of $12 \mathrm{~s}$. per week and the private rooms at the rate of $£ 33 s$. per week have come from all parts of London. The former have necessarily been restricted to patients from the districts naturally served by the hospital and as regards the latter applications from the neighbourhood receive preference. These charges serve as a working basis, variations being, of course, made in special circumstances, and the provision of the beds at the higher ratc beins: made for the benefit of those only who cannot properly afford the charges in an ordinary nursing home.

I am given to understand that at least one of the London hospitals which have accommodation of this kind restricts the practice to consultants but the course adopted in the Hampstead General Hospital, and which appears to be growing in favour, is that the patients shall be attended by their ordinary medical attendants, and that the necessary arrangements for the attendance of consulting physicians or surgeons shall be left in their hands.

I am, Sirs, yours faithfully, ERnest Collins, Chairman of the Council.

Hampstead General Hospital, Haverstock Hill, N.W. March 28th, 1906.

Royal Army Medical Corps Volunteers (LONDON COMPANIES).- - O o March 31st a smoking concert was held by the London Companies of the R.A.M.C. Volunteers at their headquarters, 51, Calthorpe-street, Gray's Inn-road, to bid farewell to Mr. G. Small, late sergeant-major and senior instructor to the corps. During an interval in the proceedings a framed address and purse of money, subscribed by members of the corps past and present, were presented by the commanding officer, Colonel V. Matthews, who spoke warmly of Mr. Small's good influence on the corps during his connexion with it, wbich extender, off and on, over a period of nearly 22 years, ever since its first inception, and paid at the same time a graceful tribute to $\mathrm{Mr}$. Small's high personal character. In thanking the donors, Mr. Small expressed the great pleasure that he experienced in accepting the gift and recalled many interesting incidents which occurred during his period of office. That there was much musical talent in the corps was evidenced by the lengthy nature of the programme provided, Colonel Matthews and most of the other officers taking an active part in the proceedings. 


\section{TEMPERANCE LEGISLATION IN FRANCE.}

Can England Profit by The Fremch Example?The Difficulty of OBTaINING "Hygienic DRINKS." -Pure Wine a't Five Fartihings the PINT in France and Fivepence in England.

(From our SPECTAL SANITARY CommissIoNER.)

\section{PART III.}

IT has been necessary to insist at length on what has occurred in Paris, because in no other part of the country has the abolition of octroi dues on "hygienic drinks" involved anything like so great a sacrifice. The Bulletin de Statis. tique, published in May, 1900, by the Minister of Finance, estimates the gross receipts of all the ootrois in France at $£ 13,327,700$, from which are deducted $£ 1,200,000$ as cost of collection. Out of this the octroi of Paris takes about halfnamely, $£ 6,256,420$. The octroi duties on wines, beer, and cider throughout France amounted to $£ 3,466,440$ and of this amount two-thirds were paid at the Paris octrois, where the duty on "hygienic drinks" used to be so much higher than in any other part of the country. Apart, however, from the action of the municipalities it is necessary to take into consideration the sacrifices made by the State in the cause of temperance. From the fiscal point of view there were three categories : first, wine, cider, perry, and mead; secondly, spirits, brandies, liqueurs, absinthes, and other alcoholic liquids; and thirdly, beer. The first category had to pay a tax for "the right of circulation" from one to two francs the hectolitre of wine according to the department from which the wine came and the place to which it was to be sent For cider, perry, and mead this tax was uniformly 80 centimes. Then the right to sell retail was taxed by the State ad valorem $12 \frac{1}{2}$ per cent. of the sale price. Spirits paid a general tax of 156 francs 25 centimes per hectolitre of pure alcohol. On beer a brewing tax was imposed of 3 francs 75 centimes per hectolitre of strong beer and 1 franc 25 centimes per hectolitre of thin beer. Under the new régime the State, as well as the municipality, sacrifices all taxation on " hygienic drinks" except the very trivial charge made for the " right to circulate." That is to say, that on wine not drunk where it is made must be paid 1 franc 50 centimes (or $1 s .3 d$.) per hectolitre (or 22 gallons) for permission to send it to other parts of the country. For cider, perry, and mead this tax is only $8 d$. for $2 ?$ gallons. For brewing the tax has been reduced to 25 centimes per degree of alcohol per hectolitre, which in practice amounts to a tax of about $1 s$. for every 22 gallons. On the other hand, the State increased the general tax on spirits from 156 francs 25 centimes to 222 francs the hectolitre. In rural and all other districts this tax on spirits must be paid to the State and if spirits are sent to towns the tax is increased from 7 francs 50 centimes to 30 francs the hectolitre. In Paris, where over and above these State charges the octroi dues have been doubled, the total of the State and local taxes on spirits amounts to no less than 415 francs or $£ 1612 \mathrm{~s}$. the hectolitre or 22 gallons. In England the tax on spirits is $£ 13$ and in Rus.ia $£ 20$ the hectolitre. By increasing the tax on spirits the annual revenues of the State have been augmented to the extent of about $£ 400,000$ and those of the city of Paris, though increased, were, as already related, $£ 280,000$ less than they would have been had the inhabitants continued to drink as much spirits as before. To the State the loss on the almost complete removal of the taxation on " hygienic drinks" has been $£ 1,704,408$, which, though considerable, is less than that experienced by the city of Paris. The State loss on cider and beer does not amount to more than about $£ 28,000$. The first year after the application of the new system it was ca'culated that by the abolition of the taxes on "hygienic drinks" the State lost in revenue $£ 1,431,064$. This is a good price to pay so that the people may have wholesome wine at cheap rates but it is a smaller sacrifice than that incurred by the city of Paris. At the lowest computation-that is, counting economies made in the cost of collecting and adding to this other offsets-the net loss was set down at $£ 1,707,388$. 'Thus, and at the lowest estimate, the city of Paris and the French nation sacrificed $£ 3,128,452$ during the first year that these reforms were

1 Parts I. and II. were published in The LaxceT of March 10th 1 Parts I. and II. were published in
(p. 709) and 24 th (p. 865$)$, 1906, respectively. applied. This is the sum paid during the course of one year so that the French people might obtain the most plentiful supply possible of "hygienic drinks" almost entirely free from taxation, whether State or local.

If the entente munioipale, of which we have heard so much of late, is to mean anything more than a demonstration of political sympathy between the capitals of the two nations concerned, surely this bold legislative and municipal attempt to deal with the temperance question should be carefully considered on this side of the Channel Naturally, it will suggest the question whether it is possible to place "hygienic drinks" within the reach of the British public. It is true that we are not a wine-growing country, but beer is recognised as a "hygienic drink" if properly made. Already in the House of Commons a Pure Beer Bil was recently introduced stipulating that not less than 85 per cent. of the saccharine-yielding material employed shall be barley malt, without any addition other than hops, yeast and water. The Bill was rejected but other similar efforts will be made. If ultimately some such law is rigorously applied it might then be safe to conclude that English-made beer had become a "hygienic drink"; but would it be a cheap drink? Mr. Scott Wood,.a director of Messrs. M. B. Foster and Sons, is reported by the Tribune to have stated to its representative that such a provision would not affect Bass's ale, "but many brewers of the cheaper table ales, 'the 2s. 6d. ales,' employ rice, grain (i.e., maize), and sugar. These brewers would find much of their plant useless under the Bill and the 2s. 6d. ales could not be profitably produced."

Of conrse, Munich beer, protected by laws more than 500 years old which render it a criminal offence to make beer with anything else whatsoever except barley-malt, hops, yeast, and water, may be considered an "hygienic drink." This was set forth by our investigations carried out on the spot and the minute analyses of the beer. ${ }^{2}$ Further, Munich beer is cheap enough-in Munich. But what with duty and the cost of transport in ice it is not retailed in London at less than $5 d$. or $6 d$. the half litre and it does not contain half as much alcohol as sound French wines which can be bought in London for the same price-namely, 10d. to 1s. the litre. On the other hand, the ordinary English. man, especially if he belongs to the working-classes, would probably take more willingly to Munich beer than to genuine French vin ordinaire mixed at table with about 50 per cent. of fresh water. Indeed, the idea of mixing wine with water is quite foreign to the English mind; yet it is the universal custom in France, and what a pleasant thirst quencher this provides in the hot, dry days of summer. Beer brewed in this country should be pure and cheap and no doubt such beers exist. At the same time and in the absence of any law beer is often made with glucose, which, it will be remembered, has been found to contain arsenic. The purchaser does not know what he is drinking; there is no legal guarantee of wholesomeness. The same may be said of many other countries and the one State that stands before the world as a molel in this respect is Bavaria. That is why Munich beer comes to the front when mention is made of " hygienic drinks."

Now, however, that more wine is produced in France than can be sold, the question arises whether wine might not serve the purpose of a "hygienic drink" in England as well as in France. In considering this matter it will be found that there are not many people on this side of the Channel who know how very cheap wine has become. Some few years ago, and before the abolition of the octroi on wine, there was a specially abundant vintage. Consequently wine trains were despatched to the outskirts of Paris and there shunted on sidings. The people were invited to come with all the pitchers and pots and pans that they could find and to buy wine contained in the great iron tanks carried by the train. The price was 15 centimes the litrethat is, less than a penny a pint. Now to-day that the octro $i$ on wine is abolished, and even when the vintages are not so very plentiful, wine can be purchased within the walls of Paris at 20 centimes or $2 \bar{d}$. the litre. This is certainly the lowest price and the majority of people pay more. But a well-known grocer, whose shops are in all parts of Paris and who is especially patronised by the British colony, Felix Potin, offers in his price list red wine "guaranteed pure" at 25 centimes the litre. This firm claims to sell 60,000 litres or bottles of wine per day. So 